\title{
Surgical treatment of hallux valgus using a modified Reverdin-Isham technique
}

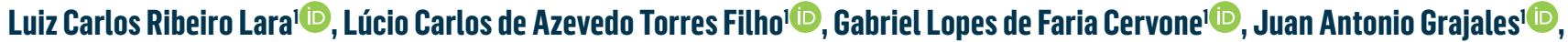 \\ Glaucia Bordignon' ${ }^{(\mathbb{D})}$, Lara Furtado Lancia' ${ }^{(\mathbb{D})}$, Diego Vitor Braga Santos ${ }^{10}$ \\ 1. Hospital Municipal Universitário de Taubaté, Taubaté, SP, Brazil.
}

\begin{abstract}
Objective: To evaluate the postoperative results of patients who underwent surgical treatment of hallux valgus with a modified Reverdin-Isham (RI) technique and to compare the achieved correction with that reported by studies using the original technique.

Methods: This is a retrospective study including patients with mild to moderate hallux valgus who underwent surgery from June 2010 to July 2019. All patients were operated using the modified RI technique. Data were collected through the American Orthopaedic Foot and Ankle Society (AOFAS) questionnaire, in addition to pre and postoperative radiographic studies of the intermetatarsal angle (IMA), the hallux valgus angle (HVA), and the distal metatarsal articular angle (DMAA).

Results: The mean postoperative follow-up was 30.1 months, and the mean age of patients was 56.4 years. The median AOFAS score in the postoperative period was increased by 56 points. The mean HVA was reduced in $16.5^{\circ}$, the mean IMA was reduced in $4.3^{\circ}$, and the mean DMAA was reduced in $10^{\circ}$. There were no cases of displacement or deviation of the first metatarsal head during the postoperative follow-up.

Conclusion: The modified RI technique provided considerable stability to the osteotomy, in addition to a significant correction of the measured angles and an improvement in AOFAS scores, demonstrating itself as an effective technique for correcting mild to moderate hallux valgus.
\end{abstract}

Level of Evidence IV, Therapeutic Studies, Case Series.

Keywords: Hallux valgus; Minimally invasive surgical procedures/instrumentation; Osteotomy/surgery; Treatment outcome.

\section{Introduction}

Hallux valgus is the most common deformity of the forefoot and is frequently accompanied by pain complaints, especially with the use of shoes with a narrow toe box. In symptomatic cases, surgical treatment is recommended, aiming to correct the alignment of the first radius. Recent studies have demonstrated that minimally invasive techniques present similar results to open surgery techniques, with less aggression to soft tissues ${ }^{(1-3)}$.

The Reverdin-Isham (RI) percutaneous surgical technique for correcting the hallux valgus deformity was developed by Stephen Isham ${ }^{(3)}$, modifying the osteotomy performed in the first metatarsal (M1) proposed by Louis Reverdin (4). The RI technique is performed through incisions of less than a centimeter ${ }^{(5)}$, following a series of surgical gestures for correcting the deformities: exostectomy, M1 osteotomy, lateral capsulotomy, adductor tenotomy, and wedge osteotomy of the base of the proximal phalanx (Akin osteotomy).

During the learning curve of the use of the RI technique, in some cases the M1 osteotomy became unstable, progressing to medial displacement of the metatarsal head. By analyzing these cases, we decided to change the way the M1 osteotomy was performed(6), seeking better stability. Other instances of the original technique were maintained as proposed by Isham(3).

The aim of this study was to evaluate postoperative results of patients who underwent surgical treatment of hallux valgus through a modified RI technique and to compare the achieved correction with that reported by studies using the original technique.
Study performed at the Hospital Municipal Universitário de Taubaté, Taubaté, SP, Brazil.

Correspondence: Luiz Carlos Ribeiro Lara. 1551 Italia Av., Jardim das Nações, Taubaté, SP, Brazil, Zip Code: 12030-212. E-mail: luizrlara@hotmail.com. Conflicts of interest: none. Source of funding: none. Date received: March 15, 2021. Date accepted: April 01, 2021. Online: April 30, 2021
How to cite this article: Lara LCR, Torres Filho LCA, Cervone GLF, Grajales JA, Bordignon G, Lancia LF, Santos DVB. Surgical treatment of hallux valgus using a modified Reverdin-Isham technique. J Foot Ankle. 2021;15(1):49-53. 


\section{Methods}

This study was approved by the Institutional Review Board and registered on the Plataforma Brasil database under CAAE (Ethics Evaluation Submission Certificate) number: 32408320.5.0000.5501.

From June 2010 to July 2019, 76 patients with mild to moderate hallux valgus underwent surgery at our institution's university hospital and one of the author's private practice. The procedure was performed percutaneously, according to Isham $^{(3)}$, with our modification(6).

We included patients with symptomatic hallux valgus classified as mild or moderate ${ }^{7}$ and who had a postoperative follow-up of at least 6 months.

Patients with severe hallux valgus, rheumatic diseases, neurological disorders, radiographic evidence of osteoarthritis in the metatarsophalangeal joint of the hallux ${ }^{(7)}$, history of previous surgery, or previous fractures of the assessed forefoot were excluded.

Patients were contacted by telephone and 69 individuals ( $90.79 \%$ of the total) attended outpatient visits, totaling 79 feet. All participating patients were informed of the objectives of this work and signed a free and informed consent form. Radiographs were performed in a weight-bearing manner in anteroposterior (AP) and lateral views, as routine. Angles were manually measured with a goniometer using the AP radiograph in the pre and postoperative periods. We measured the hallux valgus angle (HVA), the intermetatarsal angle (IMA), and the distal metatarsal articular angle (DMAA) ${ }^{(8)}$.

All measurements were performed by orthopaedic specialists of the foot and ankle surgical team of our service.

Clinical assessment was performed using a translated version of the American Orthopaedic Foot and Ankle Society (AOFAS) questionnaire for hallux deformities ${ }^{(9)}$. The range of motion of the first interphalangeal and metatarsophalangeal joints was measured with a goniometer, both pre and postoperatively.

All complications after the procedure were documented in the medical records. These included complications of the surgical wound, sensitivity or motor alterations of the hallux, residual calluses or deformities or of the smaller toes, unpredicted displacements of the metatarsal osteotomy, delayed union (absence of consolidation after 8 weeks), recurrences, or progression to osteodegenerative changes.

\section{Surgical technique}

The procedures were performed by a team comprising 2 orthopaedists specialized in foot and ankle surgery. Patients were positioned in the dorsal decubitus position with their feet protruding from the operating table, without the use of a tourniquet, and were subjected to locoregional anesthesia (ankle block) at the ankle ${ }^{(10)}$.

The special material used for surgery included a MIS Beaver 64 scalpel blade, a Wedge $4.1 \mathrm{~mm}$ burr, a long Shannon burr, and rasps. For the movement of the percutaneous burrs, we used a motor drill at $6000 \mathrm{rpm}$.
All patients were subjected to the RI technique, which included exostectomy, lateral capsulotomy, adductor tenotomy, and Akin osteotomy, performed according to the literature $^{(3,4,11)}$. Our modification was on the distal M1 osteotomy.

Exostectomy - this procedure was performed via a $5-8 \mathrm{~mm}$ incision on the medial plantar surface of the M1. Firstly, a single-plane incision was made, reaching the end of the exostosis. The articular capsule was detached from the bone. Then, the Wedge burr was used for removing the exostosis. The bony detritus was removed manually and by washing with saline solution.

Modified RI osteotomy - after removing the exostosis and under fluoroscopy guidance, the Shannon burr was positioned through the same incision on the medial surface of the $M 1$, at an angle of $45^{\circ}$ to the ground and immediately proximal to the medial sesamoid bone, pointing to the second metatarsal head. The osteotomy was initiated until reaching one-third of the metatarsal width. At this point, the direction of the burr was changed to a position perpendicular to the long axis of the metatarsal bone, maintaining the transversal cut until it reached the final third of the bone width. The direction of the burr was again changed to proximal and oblique until the lateral cortex osteotomy was completed. The aim was to create a notch where, when laterally translating the $M 1$ head, a natural fit of the bone fragments occured (Figure $1 \mathrm{~A}$ and $\mathrm{B}$ ), providing more stability to the osteotomy.
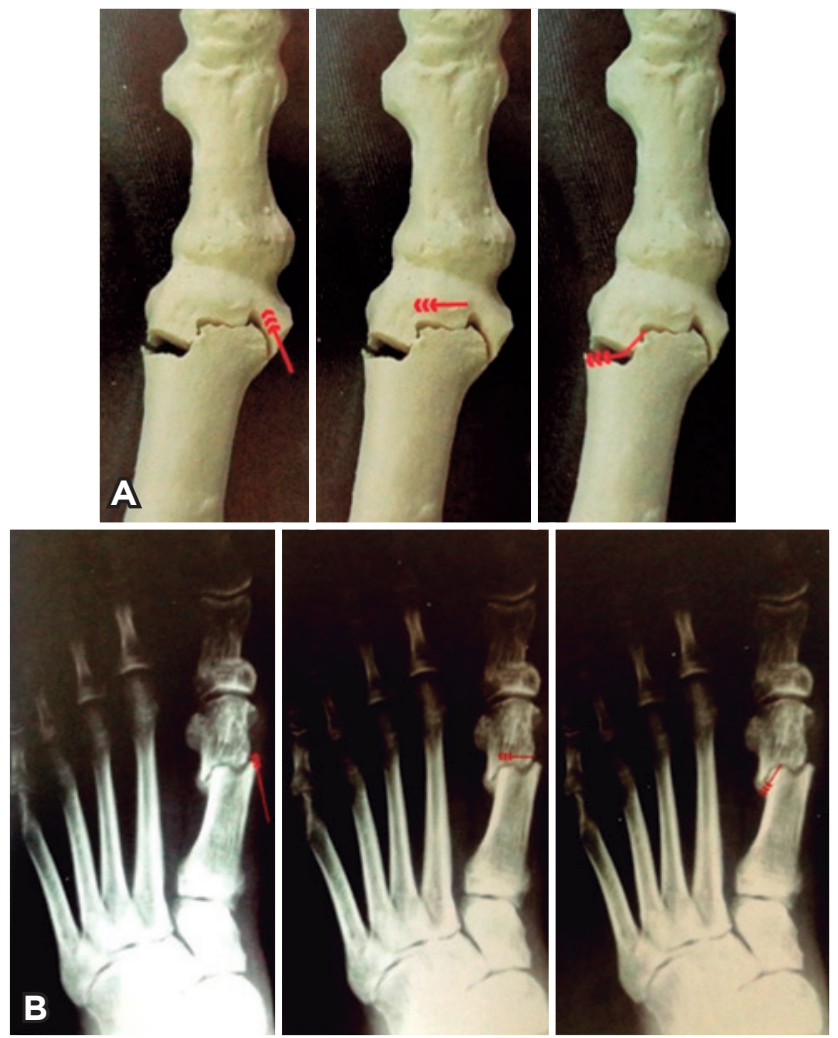

Figure 1. A. Sequence of M1 osteotomy planes in Sawbones. B. Same sequence demonstrated in radiographs. 
Tenotomy of the adductor hallucis tendon and lateral capsulotomy - Through a new $2 \mathrm{~mm}$ incision in the dorsal lateral surface of the first metatarsophalangeal joint, the adductor hallucis tendon and the lateral capsule were sectioned.

Hallux proximal phalanx base osteotomy (Akin osteotomy) ${ }^{(11)}$ - through another 3-5mm incision in the dorsal medial surface of the base of the first phalanx, medial osteotomy was performed with a long Shannon burr without reaching the lateral cortex, maintaining higher stability with the osteoclasis after varus movement of the toe.

\section{Immobilization and postoperative care}

At the end of the procedure, we applied an elastic bandage for maintaining the achieved position in a slight hypercorrection of the hallux. This immobilization should be changed weekly by the team during the first 4 weeks, and by the patient in the 2 following weeks. Deambulation was allowed with the use of shoes with stiff soles from the first day until the second month after the procedure. The patient was instructed to mobilize the hallux from the first week. Physiotherapy was recommended after the sixth postoperative week

\section{Statistics}

Initially, the demographic and clinical characteristics were descriptively analyzed. Categorical variables were presented as absolute and relative frequencies, and numerical variables were presented as summary statistics (mean, median, standard deviation [SD], minimum, maximum).

For comparing means before and after intervention, we used a Student's t-test for paired samples. The Student's t-test assumes a normal distribution, which was verified using a Kolmogorov-Smirnov test. All statistical tests used a significance level of $5 \%$.

Statistical analyses were performed with SPSS 20.0.

\section{Results}

We analyzed information from 69 patients and 79 feet. The mean age was 56.4 years ( $S D=11.9$ years), minimum age was 27 years, and maximum age was 82 years.

As shown in table 1, 91.3\% of the patients were female, $14.5 \%$ had both their feet affected, and $51.9 \%$ of the cases were of the left foot. Mean follow-up was 30.1 months ( $S D=20$ months), with a minimum period of 6 months and a maximum of 98 months (a little over 8 years).

As shown in table 2, significant reductions were observed in the HVA $(p<0.001)$, the IMA $(p<0.001)$, and the DMAA $(p<0.001)$. An improvement of the AOFAS score was also observed $(p<0.001)$. This way, mean reductions of $16.5^{\circ}$ $\left(\mathrm{SD}=7.3^{\circ}\right), 4.3^{\circ}\left(\mathrm{SD}=2.7^{\circ}\right)$, and $10.0^{\circ}\left(\mathrm{SD}=7.7^{\circ}\right)$ were observed in the HVA, IMA, and DMAA, respectively. Considering the AOFAS score, we verified a significant increase in the median value, with a variation of 56 points $(p<0.001)$

Regarding complications, $79.7 \%$ of the feet (63) did not present any type of complication. The most frequent occurrence was a limitation of the range of motion of the metatarsophalangeal joint, in only $6.3 \%$ (5) of the feet, followed by hypoesthesia, reflex sympathetic dystrophy, and persistent edema, with 2 cases each. Transfer metatarsalgia and second metatarsal stress fracture occurred only in one patient each, as well as one recurrence and one hypercorrection (hallux varus).

Table 1. Sample characteristics

\section{Patients ( $N=69)$}

$\begin{array}{lc}\text { Sex, N (\%) } & 63(91.3) \\ \text { Female } & 6(8.7) \\ \text { Male } & \\ \text { Age (years) } & 56.4 \pm 11.9 \\ \text { Mean } \pm \text { SD } & 57.0(27.0 \text { to } 82.0) \\ \text { Median (minimum - maximum) } & 59(85.5) \\ \text { Involvement, N (\%) } & 10(14.5) \\ \text { Unilateral } & \\ \text { Bilateral } & \\ \text { Feet (N=79) } & 38(48.1) \\ \text { Laterality, N (\%) } & 41(51.9) \\ \quad \text { Right } & \\ \text { Left } & 30.1 \pm 20.0 \\ \text { Follow-up (months) } & 24.0(6.0 \text { to } 98.0) \\ \text { Mean } \pm \text { SD } & \\ \text { Median (minimum - maximum) }\end{array}$

Table 2. Measured variables

\begin{tabular}{|c|c|c|c|c|}
\hline & \multicolumn{3}{|c|}{ Time points } & \multirow[b]{2}{*}{$\mathbf{p}$} \\
\hline & $\begin{array}{l}\text { Before } \\
\text { surgery }\end{array}$ & $\begin{array}{c}\text { After } \\
\text { surgery }\end{array}$ & $\begin{array}{l}\text { Before-after } \\
\text { surgery }\end{array}$ & \\
\hline $\begin{array}{l}\text { Hallux valgus } \\
\text { angle (0) }\end{array}$ & & & & $<0.001$ \\
\hline Mean \pm SD & $27.5 \pm 6.9$ & $10.9 \pm 5.6$ & $-16.5 \pm 7.3$ & \\
\hline $\begin{array}{l}\text { Median (minimum } \\
\text { - maximum) }\end{array}$ & $\begin{array}{l}27.0(10.0 \\
\text { to } 45.0)\end{array}$ & $\begin{array}{c}10.0(-10.0 \\
\text { to } 25.0)\end{array}$ & $\begin{array}{c}-16.0(-36.0 \\
\text { to }-2.0)\end{array}$ & \\
\hline $\begin{array}{l}\text { Intermetatarsal } \\
\text { angle (0) }\end{array}$ & & & & $<0.001$ \\
\hline Mean \pm SD & $14.6 \pm 2.7$ & $10.2 \pm 2.5$ & $-4.3 \pm 2.7$ & \\
\hline $\begin{array}{l}\text { Median } \\
\text { (minimum - } \\
\text { maximum) }\end{array}$ & $\begin{array}{l}14.0(8.0 \\
\text { to } 20.0)\end{array}$ & $\begin{array}{l}10.0(5.0 \\
\text { to } 19.0)\end{array}$ & $\begin{array}{c}-4.0(-11.0 \\
\text { to } 6.0)\end{array}$ & \\
\hline $\begin{array}{l}\text { Distal metatarsal } \\
\text { articular angle (o) }\end{array}$ & & & & $<0.001$ \\
\hline Mean \pm SD & $17.7 \pm 8.1$ & $7.6 \pm 4.2$ & $-10.0 \pm 7.7$ & \\
\hline $\begin{array}{l}\text { Median } \\
\text { (minimum - } \\
\text { maximum) }\end{array}$ & $\begin{array}{l}17.0(0.0 \\
\text { to } 50.0)\end{array}$ & $\begin{array}{c}6.0 \text { (0.0 to } \\
20.0)\end{array}$ & $\begin{array}{l}-10.0(-32.0 \\
\text { to } 5.0)\end{array}$ & \\
\hline AOFAS score & & & & $<0.001$ \\
\hline Mean \pm SD & $40.2 \pm 12.8$ & $92.9 \pm 6.0$ & $52.7 \pm 13.2$ & \\
\hline $\begin{array}{l}\text { Median } \\
\text { (minimum - } \\
\text { maximum) }\end{array}$ & $\begin{array}{c}35.0(23.0 \\
\text { to } 74.0)\end{array}$ & $\begin{array}{l}95.0(74.0 \\
\text { to } 100.0)\end{array}$ & $\begin{array}{l}56.0(13.0 \\
\text { to } 72.0)\end{array}$ & \\
\hline
\end{tabular}




\section{Discussion}

Mean AOFAS scores were significantly increased, going from a median of 35 points before surgery to 95 points after the procedure, demonstrating a median variation of 56 points; this is similar to what was reported by studies using the classical RI technique ${ }^{(12,13)}$. On the other hand, scores were slightly inferior to what was reported by Restuccia et al. ${ }^{(14)}$ and Liuini et al. (2). We believe that our AOFAS score variation was lower because we did not include patients with severe hallux valgus, which are generally associated with lower preoperative AOFAS scores.

We observed a significant decrease in the measured radiological angles. The mean HVA was decreased by $16.5^{\circ}$, indicating good correction of this parameter when compared to results of authors using the traditional technique ${ }^{(12,13,15)}$.

In this study, we performed complete osteotomy of M1 and lateral displacement of the distal fragment. We reckon that this is the reason why we achieved a higher correction of the IMA when considering studies that used the classical RI procedure $^{(12,13,15)}$. The mean DMAA was decreased by $10^{\circ}$, which is in line with values observed in the literature ${ }^{(4,12-18)}$.

The modified RI technique maintained the intracapsular aspect of the original description (1). Therefore, we do not recommend this procedure for cases of severe hallux valgus, where there is a need for increased angular correction.

The most frequent complication of percutaneous intracapsular techniques and open surgeries tends to be the decrease of the range of motion of the hallux metatarsophalangeal joint ${ }^{(4,12,15,19)}$. Although all patients were instructed to actively mobilize the joint in the immediate postoperative period, the results of this study were also in line with the literature, showing a decrease in mobility as the most frequent complication (6.3\%).

Even though it is not frequent with the classical RI technique, displacement of the M1 osteotomy may occur, leading to the loss of the achieved correction ${ }^{(1,10,15,20,21)}$. We aimed to modify the RI technique so that the M1 osteotomy would promote the fit of the bone fragments, providing better stability ${ }^{(5)}$. With this modification, we did not observe any cases of osteotomy displacement.

Hallux hypoesthesia was observed in 2 patients (2.5\%), with a low incidence when compared to the literature, where some studies report indices of up to $30 \%{ }^{(6)}$. We believe that this type of complication occurs due to overheating of the burrs and its potential aggression to soft tissues. To reduce the risk of injury, one should maintain motor rotation below 8000 rpm, avoid continuous and prolonged use of the burr, and perform intermittent irrigation with physiological saline. These measures help cooling the burrs, avoiding burns to the skin and soft tissues ${ }^{(22)}$.

We had a case of transfer metatarsalgia and a third metatarsal stress fracture. We believe that these complications are due to the association between the shortening caused by the M1 osteotomy and the long second and third metatarsals. This combination can lead to the inbalance of the metatarsal formula, leading to an overload of the neighboring radiuses ${ }^{(4,23)}$.
We had only one case of recurrence, where the patient opted to not undergo a new correction procedure since she was not having symptoms.

Three patients (3.8\%) had type 1 complex regional pain syndrome (PRPS) after the procedure, reaching spontaneous resolution up to 6 months into the postoperative period ${ }^{(24)}$. This result was in line with the literature, where a systematic review of foot and ankle surgeries reported an incidence of PRPS of $4.36 \%{ }^{(25)}$. Bauer et al. had an incidence of $2.67 \%$ with percutaneous surgeries, but of type 2 PRPS, with neurological injury ${ }^{(13)}$.

In the literature, infection rates for percutaneous foot surgeries vary from $0 \%$ to $3.5 \%{ }^{(16,22,26)}$. We did not report any infections in the present study and we believe that this could be justified by a low aggression to tissues and minimal bone exposure, as described by Prado et al. ${ }^{(4)}$.

Some of the positive aspects of our work include a satisfactory sample size, where we managed to perform a 6-month follow-up with approximately $90 \%$ of the patients and the mean follow-up lasted 30.1 months. Our pre and postoperative assessments approached both objective radiographic measurements (angle variations) and the functional assessment of patients (clinical assessment and AOFAS questionnaire).

Despite being one of the most widely used questionnaires, the AOFAS score has little validation in the literature due to its limitations in clinical assessment ${ }^{(18,27)}$. We decided to use this instrument because it provided us with a wider bibliographic study for analyzing the obtained clinical results.

As limitations of this study, we should cite that data were collected by more than one examinator. All pre and postoperative assessments were executed by the same team of surgeons that performed the experiments, which could be a source or performance bias. We did not assess shortening of the metatarsal after osteotomy, which could be useful for discussing possible transfer metatarsalgias. Angle measurements were performed manually, which could result in interobserver variations. Since this is a retrospective study for evaluating the results of a single surgical technique, we did not have a control group for comparing results. For future studies, we suggest the comparison between patients who underwent the original surgical technique and our modified procedure, evaluating their capacity to avoid displacements of the M1 head.

In percutaneous foot surgery, in addition to an adequate indication and specific material, it is crucial that the surgeon undergoes training for familiarizing him or herself with the technique and for the progression of the learning curve. The learning curve is known to be long ${ }^{(28)}$, but as one progresses, the level of complications inherent to the surgeon decreases.

\section{Conclusion}

The modification of the M1 osteotomy in the RI technique evidenced significant results regarding its stability, since there were no displacements or deviations in the postoperative period. We observed a significant improvement in AOFAS scores and in the correction of the measured angles. Therefore, the modification was shown to be effective for correcting mild to moderate hallux valgus. 
Authors' contributions: Each author contributed individually and significantly to the development of this article: LCRL *(http://orcid.org/OOOO-OOO31158-2643) Conceived and planned the activities that led to the study, wrote the article, participated in the review process, performed the surgeries, data collection, bibliographic review, clinical examination; LCATF *(https://orcid.org/0000-0002-0778-2506) Conceived and planned the activities that led to the study, performed the surgeries, data collection, clinical examination; GLFC *(https://orcid.org/0000-0001-5470-8379) Conceived and planned the activities that led to the study, performed the surgeries, data collection, clinical examination; JAG *(https://orcid.org/0000-0003-4652-4400) Conceived and planned the activities that led to the study, performed the surgeries, data collection, clinical examination; GB *(https://orcid.org/0000-0001-52734303) Wrote the article, interpreted the results of the study, participated in the review process, statistical analysis, bibliographic review, survey of medical records, formatting of the article; LDL *(https://orcid.org/0000-0003-1048-7134) Wrote the article, interpreted the results of the study, participated in the review process, statistical analysis, bibliographic review, survey of medical records, formatting of the article; DVBS *(https://orcid.org/0000-0001-69881609) Wrote the article, interpreted the results of the study, participated in the review process, statistical analysis, bibliographic review, survey of medical records, formatting of the article. All authors read and approved the final manuscript. *ORCID (Open Researcher and Contributor ID) iD.

\section{References}

1. Prado M, Ripoll PL, Vaquero J GP. Tratamiento quirúrgico percutáneo del hallux valgus mediante osteotomías múltiples. Rev Esp Cir Ortopédica Traumatol. 2003;6(47):406-16.

2. Liuni FM, Berni L, Fontanarosa A, Cepparulo R, Guardoli A, Pellegrini $A$, et al. Hallux valgus correction with a new percutaneous distal osteotomy: Surgical technique and medium term outcomes. Foot Ankle Surg. 2020;26(1):39-46.

3. Isham SA. The Reverdin-Isham procedure for the correction of hallux abducto valgus. A distal metatarsal osteotomy procedure. Clin Podiatr Med Surg. 1991;8(1):81-94.

4. Reverdin JL. Anatomic at operation de I'hallux valgus. Int Med Congr 2:408, 1881. Int Med Congr. 1881;2:408. Cyrille C. Chirurgie mini-invasive et percutanée du pied. Broché. la ed. Sauramps Médical; Mon; 2009.

5. Lara LCR. Modified Reverdin-Isham procedure. In: Cirugía mínimamente invasiva del pie. In: Federación Latinoamericana de Medicina y Cirugía de la Pierna y el Pie. Minimally invasive foot surgery. São Paulo, SP: Triall Editorial; 2018. p 73-83.

6. Coughlin MJ, Anderson BA, Hallux Valgus. In: Coughlin Mj, Saltzman C, Anderson RB, editors. In: Mann's surgery of the foot and ankle. Philadelphia: Elsevier; 2013. p 155-309.

7. Coughlin MJ, Saltzman CL, Nunley JA 2nd. Angular measurements in the evaluation of hallux valgus deformities: a report of the ad hoc committee of the American Orthopaedic Foot \& Ankle Society on angular measurements. Foot Ankle Int. 2002;23(1):68-74.

8. Kitaoka HB, Alexander IJ, Adelaar RS, Nunley JA, Myerson MS, Sanders M. Clinical rating systems for the ankle-hindfoot, midfoot, hallux, and lesser toes. Foot Ankle Int. 1994;15(7):349-53.

9. Oliveira CL, Torres Filho LCA, Lara LCR, Cervone GF, Figueiredo R, Lancia LF. 4 in 1 and 5 - in -1 blocs in percutaneous forefoot surgery. J Foot Ankle. 2020;14(1):79-83.

10. Akin OF. The treatment of hallux valgus. A new operative procedure and its results. Med Sentinel. 1925.(33):678-9.

11. Lara LCR, Torres Filho LCA, Cervone GLF, Viana RP, Bordignon G, Grajales JA, et al. Percutaneal surgical treatment of hallux valgus: a retrospective study with 6.5 - year follow up. J Foot Ankle. 2020;14(3):248-84

12. Bauer T, de Lavigne C, Biau D, De Prado M, Isham S, Laffenétre O. Percutaneous hallux valgus surgery: a prospective multicenter study of 189 cases. Orthop Clin North Am. 2009;40(4):505-14.

13. Restuccia G, Lippi A, Sacchetti F, Citarelli C, Casella F, Benifei M. Percutaneous hallux valgus correction: modified Reverdin-Isham osteotomy, preliminary results. Surg Technol Int. 2017;31:263-66.

14. Carvalho P, Diniz P, Flora M, Domingos R, Sarafana J, Neves. Estudo retrospectivo a longo prazo da osteotomia de reverdin- isham: limitações e complicações. Rev Port Ortop e Traumatol. 2017;25(4):292-302.

15. Liuni FM, Berni L, Fontanarosa A, Cepparulo R, Guardoli A, Pellegrini $A$, et al. Hallux valgus correction with a new percutaneous distal osteotomy: Surgical technique and medium term outcomes. Foot Ankle Surg. 2020;26(1):39-46.

16. Severyns M, Carret $P$, Brunier-Agot L, Debandt M, Odri GA Rouvillain JL. Reverdin-Isham procedure for mild or moderate hallux valgus: clinical and radiographic outcomes. Musculoskelet Surg. 2019;103(2):161-66.

17. Biz C, Fosser M, Dalmau-Pastor M, Corradin M, Rodà MG, Aldegher $\mathrm{R}$, et al. Functional and radiographic outcomes of hallux valgus correction by mini-invasive surgery with Reverdin-Isham and Akin percutaneous osteotomies: a longitudinal prospective study with a 48-month follow-up. J Orthop Surg Res. 2016;11(1):157.

18. Reyes G, López E, Pérez-Sanpablo A, Galván Gastelum C, Álvarez $M$, Mendoza $F$, et al. Distribución de la presión plantar dinámica después del tratamiento correctivo de hallux valgus mediante la técnica de Reverdin-Isham. Rev Invest Clin. 2014;66(1):79-84.

19. Oliva F, Longo UG, Maffulli N. Minimally invasive hallux valgus correction. Orthop Clin North Am. 2009;40(4):525-30, x.

20. Kadakia AR, Smerek JP, Myerson MS. Radiographic results after percutaneous distal metatarsal osteotomy for correction of hallux valgus deformity. Foot Ankle Int. 2007;28(3):355-60.

21. Piqué-Vidal $C$. The effect of temperature elevation during discontinuous use of rotatory burrs in the correction of hallux valgus. J Foot Ankle Surg. 2005;44(5):336-44.

22. Maestro M, Besse JL, Ragusa M, Berthonnaud E. Forefoot morphotype study and planning method for forefoot osteotomy. Foot Ankle Clin. 2003 Dec;8(4):695-710.

23. Sociedade Brasileira de Ortopedia e Traumatologia. Tratado de dor musculoesquelética. São Paulo: ALEF; 2019. p 343-53.

24. Rewhorn MJ, Leung AH, Gillespie A, Moir JS, Miller R. Incidence of complex regional pain syndrome after foot and ankle surgery. J Foot Ankle Surg. 2014;53(3):256-8.

25. Austin DW, Leventen EO. A new osteotomy for hallux valgus: a horizontally directed "V" displacement osteotomy of the metatarsal head for hallux valgus and primus varus. Clin Orthop Relat Res. 1981;(157):25-30.

26. Vienne P, Sukthankar A, Favre P, Werner CM, Baumer A, Zingg PO Metatarsophalangeal joint arthrodesis after failed Keller-Brandes procedure. Foot Ankle Int. 2006;27(11):894-901.

27. Jowett CRJ, Bedi HS. Preliminary Results and Learning Curve of the Minimally Invasive Chevron Akin Operation for Hallux Valgus. J Foot Ankle Surg. 2017;56(3):445-52. 